\title{
APRESENTAÇÃO
}

\section{MUITOS CAMINHOS E UMA SINGELA HOMENAGEM}

Esta edição da Revista EntreLetras buscou atualizar algumas discussões recentes sobre os caminhos que têm tomado a relação dos estudos literários com a educação, seja formação inicial ou continuada e, sobretudo, na educação básica, alvo de preocupações entre críticos e teóricos da Literatura. Mesmo não havendo ineditismo nas tensões ora apresentadas, os últimos anos reacenderam questionamentos há muito sinalizados por pesquisadoras como pesquisadoras como Regina Zilberman, Marisa Lajolo, Glória Bordini, Lígia Chiappini, Maria do Rosário Mortatti, para citar apenas algumas. E, numa menção especial a uma representante importantíssima neste cenário, a Revista homenageia a professora Dr. ${ }^{a}$ Maria das Graça Paulino, falecida no dia 04 de agosto de 2019.

Graça Paulino, como era conhecida, foi graduada em Letras, mestra em Estudos Literários pela UFMG e doutora em Teoria Literária pela UFRJ. Atuou como docente na Faculdade de Letras da UFMG no início dos anos 1970, na qual permaneceu até 1994. Após esse período, tornou-se professora na Faculdade de Educação da UFMG e pesquisadora do Grupo de Pesquisa do Letramento Literário (GPELL) do Centro de Alfabetização Leitura e Escola (CEALE). Graça Paulino foi defensora do ensino de literatura, tendo como princípio o acesso de todos ao texto literário, e mostrou-se sempre preocupada com a formação do leitor literário na escola básica.

No início dos anos de 1990, sua produção teórica já estava voltada para uma discussão sobre a formação leitora e o ensino de literatura, como se pode ver pela publicação de "Ler/não ler: uma teoria da leitura literária", em Ensaios de Semiótica; "Problemas interlocutórios/intertextuais no ensino de literatura", em Cadernos de Pesquisa do Napq, de 1993; “A formação do professor como leitor literário”, em Cadernos de Educação Básica, de 1994; "A questão dos gêneros literários", no livro Teoria da literatura na escola, de 1996. Foi uma das principais teóricas do letramento literário e, como professora e teórica, defendia o acesso do leitor ao texto literário, questionando velhas práticas de ensino da literatura. Ela ajudou a formular o campo do saber literatura e ensino e a pensar a formação do leitor literário. A ela devemos a lição de como experimentar e viver o literário como leitores e docentes.

O presente volume da EntreLetras contém, além de 21 artigos do dossiê temático, um ensaio, seis textos na sessão "tema livre", duas entrevistas, uma resenha e sete textos literários. 
Recebemos, para o dossiê, um número bastante significativo de textos, contendo pesquisas concluídas e/ou em andamento. O grande interesse pela discussão em um momento em que dossiês sobre o assunto não têm sido raros mostra que o debate sobre o assunto parece estar longe de arrefecer. O conjunto de textos aqui apresentados apresenta um painel variado de caminhos da formação, dos conceitos de leitor e de um painel obras, de pesquisadores do Brasil e de países da América do Sul.

O texto que abre o volume, de Regina Zilberman, nome consagrado na área, traz um recorte histórico do subsistema literário mais presente em contexto escolar, em especial nos primeiros anos do ensino fundamental. No ano em que Flicts, de Ziraldo, comemora cinquenta anos de publicação, o texto da pesquisadora ocupa-se dele e de outros seus contemporâneos, construindo de certa forma um percurso que parte do clássico de Cecília Meireles, Ou isto ou aquilo e chega a autores representativos do momento conhecido como boom da produção brasileira dirigida à criança: Eliardo França, Ruth Rocha, Ana Maria Machado, Ziraldo, Lygia Bojunga. O painel apresentado permite perceber o projeto de formação empreendido por um grupo de autores, a partir da inovação estética de Monteiro Lobato.

Cecília Bajour, professora na Universidad Nacional de San Martín, em Buenos Aires, amplia no artigo aqui apresentado suas discussões acerca da escuta literária como prática nas aulas de leitura de literatura, tese conhecida pelos brasileiros por meio de seu livro Ouvir nas entrelinhas. A publicação bilíngue contou com tradução de Antonio Andrade, professor da Universidade Federal do Rio de Janeiro.

A formação inicial do professor de Literatura, que atuará primordialmente na educação básica, é alvo das reflexões de Benedito Antunes. No mesmo sentido da formação inicial encaminha-se o texto de Rosana Zanelatto, que tem como alvo de investigação pensar conceitual e relacionalmente três categorias: experiência, autoridade e onsciência crítica, perpassadas pelo texto literário como expressão estética. Já o texto de Ana Crelia Dias, Sergio Annibal e Vima Lia de Rossi Martin apresenta resultados de uma pesquisa sobre periódicos da área de Letras, cujos dossiês versaram sobre ensino de Literatura.

Gilmei Francisco Fleck, em seu texto, busca refletir sobre a formação do leitor no espaço escolar, construindo a argumentação da importância da leitura como "meio de descolonização em sociedades estratificadas". Ainda nos caminhos sobre a formação escolar, Juliane Santos e Hélder Pinheiro Alves apresentam uma proposta de abordagem metodológica da literatura infantil a partir da leitura de textos de Sérgio Caparelli. 
María de Los Ángeles Lugo Colina faz um percurso de leitura crítica de obras de Lygia Bojunga para investigar a representação da infância. A partir de um estudo crítico de obra da escritora paranaense Helena Kolody, Cristian Javier Lopez e Vilson Prusak dos Santos tecem considerações acerca do espaço da poesia em sala de aula.

Camila Rodrigues Viana e Janete Silva Santos caminham em direção à implementação da Base Nacional Comum Curricular nos primeiros anos do ensino fundamental, e suas visíveis implicações para a leitura literária no segmento. Já o texto de Marina Rodrigues de Oliveira faz um breve recuo no tempo para investigar a representação de duas figuras femininas: a leitora, em $A$ carne, de Júlio Ribeiro, e a professora, de $A$ Normalista, de Adolfo Caminha.

O espaço e a função da biblioteca e do bibliotecário na formação de leitores estão no centro das reflexões de Dijan Leal de Sousa e Maria José de Pinho. No mesmo sentido caminham as discussões de Eloiza Marinho dos Santos e Maria José de Pinho, que trazem relato sobre a criação de um espaço de leitura por estudantes da Universidade Federal do Maranhão, a "Geladeiroteca".

A prática pedagógica nas aulas de leitura literária de uma professora do ensino fundamental é analisada por Maria Fernanda Oliveira e Denise Barreto de Resende, num texto a quatro mãos, em que Denise é pesquisadora e também matéria pesquisada, e cenas de sua sala de aula aparecem como relatos e reflexões construídos pelas autoras. Na sala de aula da educação infantil encena-se a proposta metodológica de leitura de dois textos de cordel: Pinóquio: ou o preço da mentira (2009), de Manoel Monteiro e Pinóquio (2015), de Sírlia Sousa de Lima, em texto de Nadilza Maria de Farias Souza e Naelza de Araújo Wanderlei.

Sônia Travassos e Patrícia Corsino tecem considerações acerca da experiência da leitura de Barba Azul no contexto de uma sala de leitura, para uma classe de ensino fundamental. Já Cristina Rothier Duarte e Girlene Marques Formiga analisam material didático do curso de Letras, modalidade EaD, do Instituto Federal da Paraíba - IFPB, no que diz respeito ao ensino do gênero poema para o Ensino Fundamental II.

A partir da instalação do conceito de "educar poético", Taís Salbé Carvalho e Antônio Máximo Gomes Ferraz tratam em seu texto das relações entre leitor e leitura literária, numa travessia de um "educar que vigora no acontecer da linguagem." A obra Claro enigma, de Carlos Drummond de Andrade, constituiu corpus para realização de um trabalho que colocou em discussão as contribuições do Método Recepcional e da sequência expandida do Letramento 
Literário para a formação de leitores de poesia no Ensino Médio, em texto de Angela Maria Fernandes Pimenta e Alice Atsuko Matsuda.

Luzimar Silva de Lima e Shirlei Marly Alves analisam a contribuição dos best-sellers para a formação de leitores em contexto escolar. Já Raquel Cristina de Souza e Souza traz a análise de diários de leitura de estudantes de sétimo ano de alunos de uma escola federal, em que constam registros de recepção das obras Édipo, o maldito (reconto de Marie-Thérèse Davidson) e $O$ cão dos Baskervilles (de Conan Doyle).

Na sessão Ensaios, Eduardo Amorim Coelho, em texto intitulado "Pesquisador é nome, o que pesquisa é ação", trata da relação inseparável entre atividade docente e pesquisa. Já Renato Almeida de Moaris, na sessão Resenha, apresenta olhar crítico sobre a obra AntiLiterature: the politics and limits of representation in moderns Brazil and Argentina, de Adam Joseph Shellhorse.

Na sessão Tema livre, há seis textos que versam sobre outras questões de linguagem: "Porque o mundo é possível: a batalha de linguagem nas sociedades mundializadas", de Eguimar Felício Chaveiro; O signo "resistência” nas eleições presidenciais de 2018 no Brasil, de Luciane de Paula e Fábio Augusto Alves de Oliveira; Letramento digital no jogo League of Legends, de Letícia de Leon Carriconde e Fabiana Poças Biondo; O Brasil na República da Bruzundanga: uma discussão sobre língua, identidade e cidadania, de Lucia Maria de Assis e André Rocha Carneiro; Letramento na educação infantil: como a psicanálise pode ajudar?, de Francisco Neto Pereira Pinto, Solene Borges Gonçalves e Maria do Espirito Santo L. S. Oliveira; e A produção escrita a partir do gênero discursivo notícia por meio de sequência didática, de Cristiane Maria da Silva Santana.

Os textos da sessão Produção literária trazem aos leitores, em prosa ou verso, o talento de autores de diferentes paragens do país: de Janete Silva Santos, temos os poemas "Eu me rio", "O céu de si", "Palavras estropiadas" e "Enquadre"; "Uma cena da faculdade" é um extrato do romance de Renato Pardal Capistrano; das Poesias Noturnas I, de Walace Rodrigues, temos: "Nada", "Poesia pequenina", "Despejos", "Motor", "Acidez"; de Naiane Vieira dos Reis, temos "Sendo leitora"; “A morte do povo" é o texto de Willian Lima Canedo; de Cícero Pereira de Souza é "Um horizonte chamado jovem"; e "Do caso de amor por Pepetela" é o texto de Luiza Helena Oliveira da Silva.

Na sessão Entrevistas, a Revista traz duas importantes contribuições: Betina Ribeiro Rodrigues da Cunha, vice-presidente da Associação Brasileira de Literatura Comparada (ABRALIC) fala de sua relação com a literatura e de seu lugar como mulher e intelectual à 
frente de uma das maiores associações da área. Saulo Neiva, diretor regional para o Caribe da Agência Universitária da Francofonia (AUF), trata da literatura brasileira em contexto francófono.

Em suas mais de 500 páginas, esta edição da EntreLetras reafirma, portanto, seu compromisso com a divulgação das pesquisas das universidades públicas, com textos de autoria de pesquisadores que representam diferentes cantos do Brasil, uma contribuição da Argentina, uma da Espanha e outra do Caribe. Além disso, outras sessões concorreram para a construção de um espaço mais democrático de discussão e leitura, para além da proposta do dossiê.

A EntreLetras está esperando por sua leitura. Agradecemos a todos pela contribuição com seus textos.

Araguaína e Rio de Janeiro, 17 de novembro de 2019

Ana Crélia Penha Dias Márcio Araújo de Melo Organizadores 